\title{
MEASURED AND CALCULATED RAINFALL-RUNOFF RELATIONSHIPS IN TORRENTIAL CATCHMENTS: INSIGHTS FOR THE DESIGN PRACTICE
}

\author{
MOSER MARKUS, MEHLHORN SUSANNE \& JANU STEFAN \\ Forest Technical Service of Torrent and Avalanche Control, Department of Torrent Processes, Austria
}

\begin{abstract}
The large-scale stationary trough system that dominated Central Europe in 2012, 2013 and 2014 led to high precipitation sums in Salzburg, Tyrol and Bavaria. In the Pinzgau and Pongau regions of Salzburg, some meteorological stations registered in June 2013 the highest precipitation sums ever recorded. In the framework of event documentation and analysis, these events were analyzed in accordance with current best practice standards and state of the art technology. The positive trend towards ever denser networks of measurement stations enables an improved quantitative capturing of precipitation and discharge data, which in turn provides an increasingly comprehensive database which can be used as input for precipitation-discharge models. With the aid of this extensive database, the measured precipitation-discharge relationships for alpine (torrent) catchment areas were recalculated, using the methodology commonly employed (HEC-HMS with the SCS method), with the ultimate aim of gaining useful insights for improved measurement practice. For this study, four catchments with available water gauges and precipitation data were selected. The calculated discharge return periods ranged from HQ2 to HQ50-100. For the Schmittenbach, an already existing model could be used; for the Urslau, an event analysis from 2002 and for the Strobler Weissenbach an event analysis from 2014 provided the required input data. The load diagram of the investigated events was derived from a combination of weather radar analyses (the spatial distribution of precipitation) and precipitation values measured at individual stations (determination of precipitation intensities).
\end{abstract}

Keywords: event analysis, precipitation-runoff relationships, HEC-HMS, SCS-CN-method.

\section{INTRODUCTION}

Torrential catchments are characterized with different precipitation-discharge processes from event to event, based on pre-event conditions and rainfall intensity. A better understanding of these phenomena can be achieved with the help of intensive event documentation and analysis of past events and denser networks of measurement stations in combination with weather radar data.

The necessary input parameters with regard to terrain morphology and run-off characteristics are already very detailed due to the nearly region-wide terrain model data (DTM $10 \mathrm{~m}$, ALS $1 \times 1 \mathrm{~m}$ ), land use maps, geological detailed maps and ground maps. Over the past years the network of official precipitation stations increased, also private precipitation measurements (e.g. www.awekas.at; www.wunderground.com) and the possibility of analyzing weather radar data including snowfall limits contains suggestions for improvement concerning the precipitation database.

However, the improved basic data alone are not sufficient to be able to calculate a good precipitation-runoff relationship. Precipitation-runoff relationships for ungauged torrential catchments are difficult, the estimation of the design event is often based on empirical formulae or event documentation with silent witnesses. Simulations without precipitation and gauging data include strong simplifications, the real processes can only partially be mapped.

In this article, measured precipitation-runoff events are presented with the HEC-HMS model including the SCS method for 4 torrential catchments in Austria. 


\section{LOCAL PECULIARITIES IN TORRENTIAL CATCHMENTS PRECIPITATION}

In complex terrain, the rainfall process is characterized by a high temporal and spatial variability (Herrnegger et al. [1]). Due to the alpine characteristics with a strong altitudinal gradient and point measurements mostly in the valley floors the observation of the mean catchment rainfall is extremely difficult. Furthermore, weather extremes such as hail or snow lead to measurement errors or the malfunction of the system. Therefore, the load diagram of the investigated events can be derived from a combination with weather radar analyses to get the spatial distribution of precipitation.

\section{LOCAL PECULIARITIES IN TORRENTIAL CATCHMENTS RUNOFF OBSERVATIONS}

Uncertainties of the discharge generated from water gauging stations in torrential catchments lie in the quality of rating curves (velocity, steady or unsteady flow), stability of the channel bed and problems with sediment or bedload depositions. It can be expected that these difficulties will be extremely large during flood events.

\section{MATERIALS AND METHODS}

\subsection{Data and model settings}

The digital elevation models were generated with the help of HEC-GeoHMS from airborne laser data with a resolution of $5 \times 5 \mathrm{~m}$. Using digital terrain data, HEC-GeoHMS produces HMS input files, a stream network, sub-basin boundaries and hydrologic elements. From the possible models in HEC-HMS we used the SCS curve number $(\mathrm{CN})$ loss model to compute the cumulative losses, the SCS unit hydrograph for modelling the direct runoff and the recession method to calculate the streamflow hydrograph.

\subsection{Soil Conservation Service Method (SCS)}

The Soil Conservation Service Method (SCS-Method) relates runoff depth and rainfall during a flood event by the runoff curve number, $\mathrm{CN}$. Peak flow has been estimated using runoff depth, lag time, time of concentration and rainfall duration. Tabulated empirical values for the runoff curve number, $\mathrm{CN}$, are available for different antecedent moisture conditions, soil type and land cover (which also considers the differing hydrological surface properties of vegetation in good and poor condition). Antecedent moisture conditions are specified by three classes (dry, average, wet) and soil type by four (high, moderate, slow, very slow infiltration). For the time of concentration, the SCS-lag-formulae (1972) was used.

\section{CATCHMENT SITES}

\subsection{Schmittenbach}

The torrent Schmittenbach is located in the province of Salzburg in the alpine region of Austria and encompasses $10 \mathrm{~km}^{2}$, the gauging station is situated in hectometer 6.2 . The design flood HQ150 (recurrence interval of 150 years) is stated with $50 \mathrm{~m}^{3} / \mathrm{s}$. The mean slope of the stream is $5 \%$, the average basin slope is $20 \%$.

\subsection{Urslau}

The torrent Urslau is located in the province of Salzburg in the alpine region of Austria and encompasses $56 \mathrm{~km}^{2}$, the gauging station is situated in the middle reach in hectometer 97.2 
on the upstream side of the so called "Schattmühlwehr". The design flood HQ150 (recurrence interval of 150 years) is stated with $131 \mathrm{~m}^{3} / \mathrm{s}$ (Gunz et al., 2009). The mean slope of the stream is $1.8 \%$, the average basin slope is $20 \%$.

\subsection{Strobler Weissenbach}

The torrent Strobler Weissenbach is located in the province of Salzburg in the alpine region of Austria and encompasses $45 \mathrm{~km}^{2}$, the gauging station is situated in the lower part of the catchment, $500 \mathrm{~m}$ above the tributary Ischler Ache. The mean slope of the stream is $2.0 \%$, the river length is about $4 \mathrm{~km}$.

\subsection{Forstaubach}

The torrent Forstaubach is located at the border of Salzburg and Styria in the alpine region of Radstätter Tauern and encompasses $64.6 \mathrm{~km}^{2}$ respectively $57.2 \mathrm{~km}^{2}$ to the gauge. The gauging station is situated at hectometer 29.5. The design flood HQ150 (recurrence interval of 150 years) is stated with $140 \mathrm{~m}^{3} / \mathrm{s}$ for the entire catchment area and $130 \mathrm{~m} / \mathrm{s}$ at the gauge. The mean slope of the stream is $2.8 \%$, the average basin slope is $15 \%$.

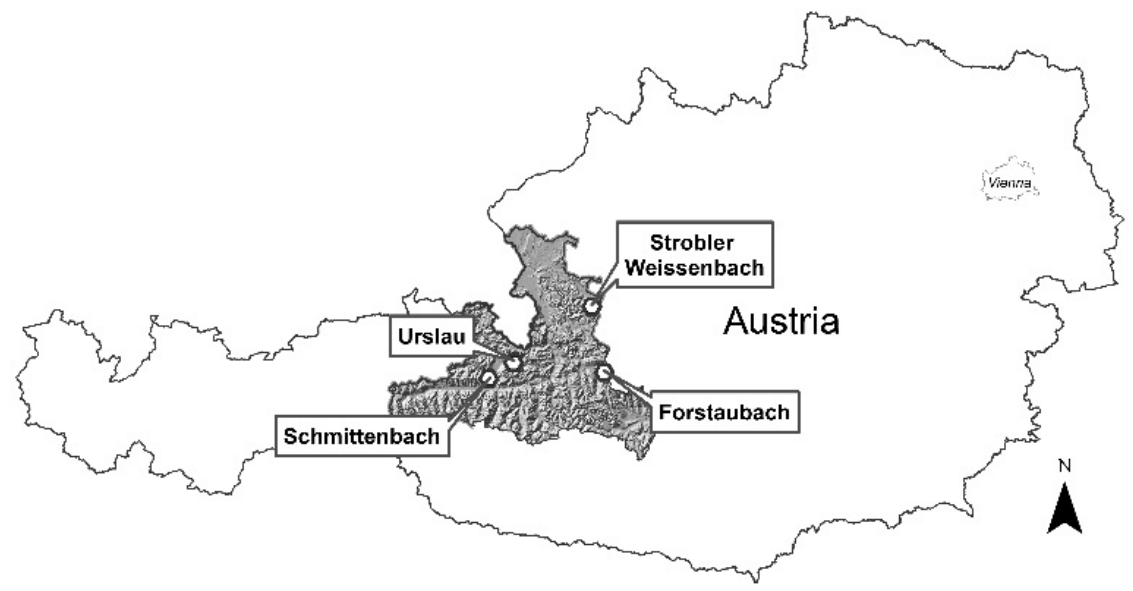

Figure 1: Catchment sites located in Austria.

Table 1: Basic data of the study catchments.

\begin{tabular}{lcccccc}
\hline & $\begin{array}{c}\text { Area } \\
\left(\mathrm{km}^{2}\right)\end{array}$ & $\begin{array}{c}\mathrm{HQ}_{150} \\
\text { design } \\
\text { event } \\
\left(\mathrm{m}^{3} / \mathrm{s}\right)\end{array}$ & $\begin{array}{c}\text { Mean } \\
\text { slope } \\
(\%)\end{array}$ & & $\begin{array}{c}\text { Land use } \\
(\%)\end{array}$ & \\
\hline & & & & Forest & Grassland & $\begin{array}{c}\text { Urban } \\
\text { area }\end{array}$ \\
\hline Schmittenbach & 10 & 50.0 & 5.0 & 80 & 18 & 2 \\
Urslau & 56 & 125 & 6.4 & 51 & 39 & 10 \\
Strobler Weissenbach & 45 & 150 & 2.5 & 50 & 40 & 10 \\
Forstaubach & 64.6 & 140 & 2.8 & 60 & 39 & 1 \\
\hline
\end{tabular}




\section{BACK-CALCULATED EVENTS}

The calculated discharge at Schmittenbach (May 2007) fits well at the rising limb of the hydrograph, the peak discharge occurred before the observed peak at the gauging station but the max. value is in line with the observed (Moser et al. [2]). The falling limb overestimates the observed values (water gauging station). The calculated Root Mean Square Error (RMSE) as standard deviation of the residuals (prediction errors) is about $+/$ $1.02 \mathrm{~m}^{3} / \mathrm{s}$ around the line of best fit.

For the Urslau the terrain morphology is different to the Schmittenbach. The strong altitudinal gradient of the catchment and the point measurement in the valley floor at the precipitation station Maria Alm did not represent the rainfall and the snowfall in the upper parts of the catchment. To take this into account, the radar data in combination with snowfall data were also used as input precipitation.

The calculated runoff with precipitation data from the station Maria Alm (Fig. 3) fits well on the rising limb, the peak and falling limb is generally underestimated. On the other hand, a general overestimation of the rising limb was calculated using the radar data.

The RMSE value of the measured and calculated data is about $+/-6.4 \mathrm{~m}^{3} / \mathrm{s}$ around the line of best fit. The same trend applies for the event 2012 at the Strobler Weissenbach, the rising limb is greatly overestimated, the peak fits well and the falling limb is quite underestimated. The calculated RMSE as standard deviation of the residuals (prediction errors) is about $+/-2.5 \mathrm{~m}^{3} / \mathrm{s}$ around the line of best fit.

The calculated discharge at Forstaubach 2002 fits well at the beginning of the rising limb. A strong overestimation has been calculated at the end of the rising limb, the peak and the falling limb are highly underestimated.

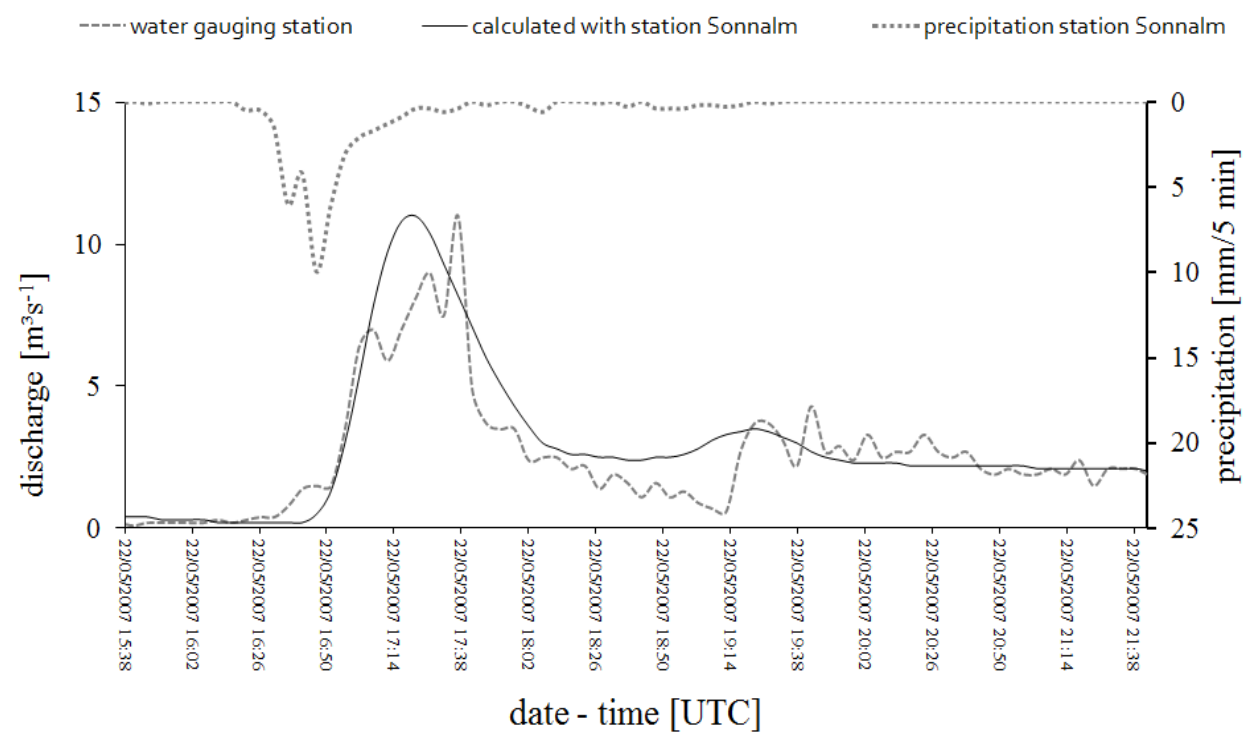

Figure 2: Schmittenbach 22.5.2007: observed and simulated data. 


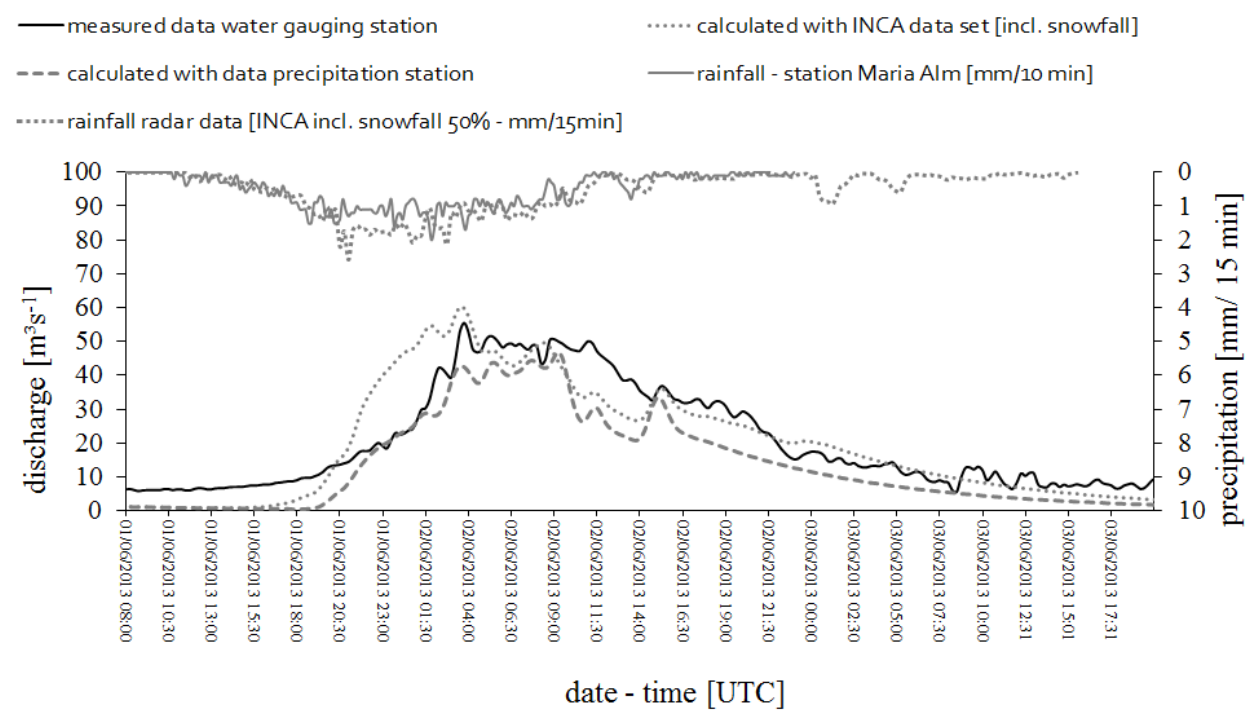

Figure 3: Urslau 01.06.2013: simulated results compared to observed data.

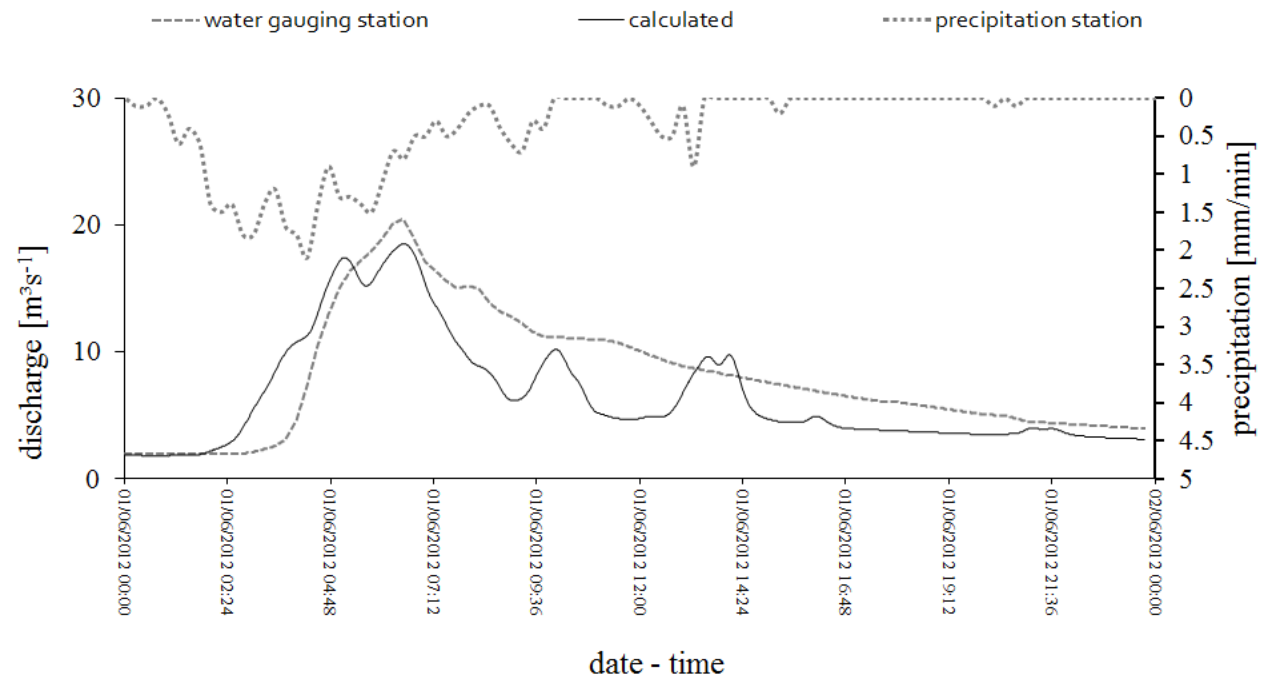

Figure 4: Strobler Weissenbach 01.06.2012: simulated and observed data. 


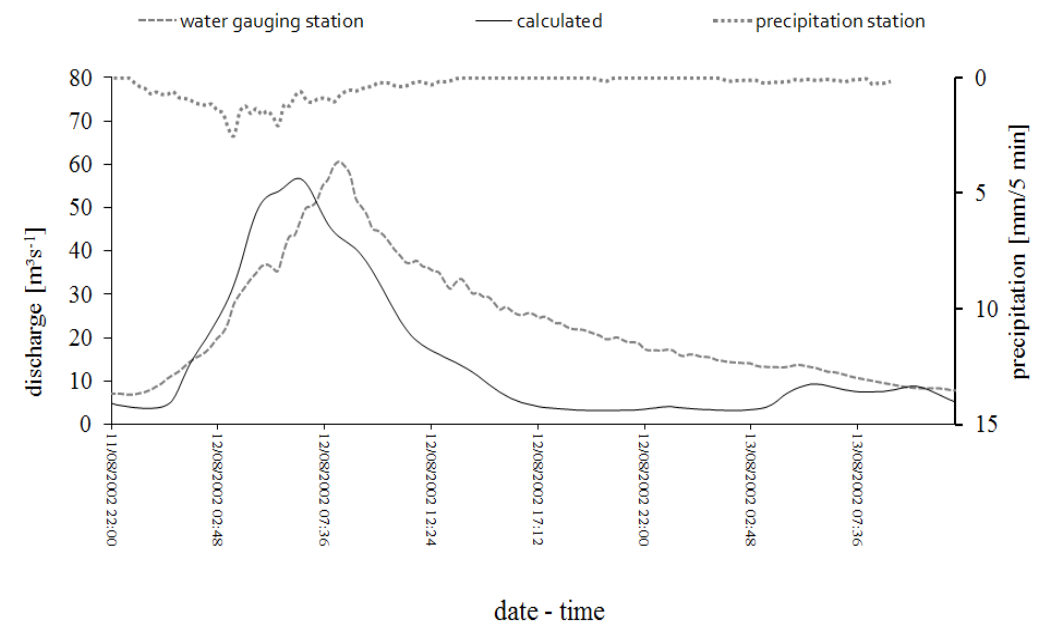

Figure 5: Forstaubach 12.08.2002: simulated and observed data.

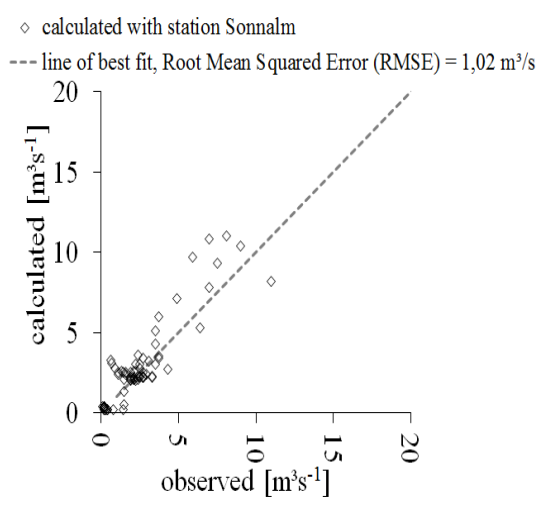

Figure 6: Observed vs. calculated (Schmittenbach).

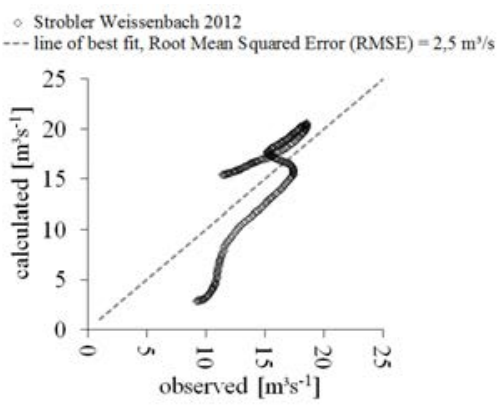

Figure 8: Observed vs. calculated (Strobler Weissenbach).
- calculated with data precipitation station

--- line of best fit, Root Mean Squared Error $(\mathrm{RMSE})=6,4 \mathrm{~m}^{3} / \mathrm{s}$

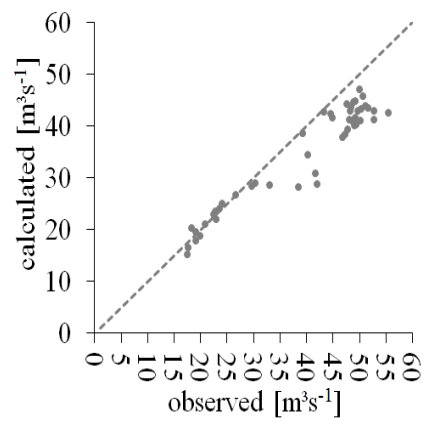

Figure 7: Observed vs. calculated (Urslau).

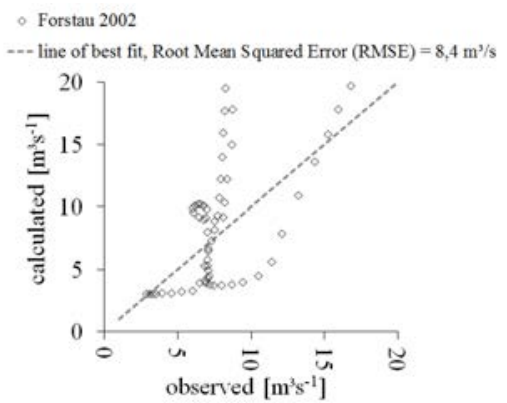

Figure 9: Observed vs. calculated (Forstaubach). 
Table 2: Catchment data and RMSE, \% variation.

\begin{tabular}{lcccc}
\hline & $\begin{array}{c}\text { Area } \\
\left(\mathrm{km}^{2}\right)\end{array}$ & $\begin{array}{c}\text { Peak discharge } \\
\left(\mathrm{m}^{3} / \mathrm{s}\right)\end{array}$ & $\begin{array}{c}\text { RMSE } \\
\left(\mathrm{m}^{3} / \mathrm{s}\right)\end{array}$ & $\begin{array}{c}\% \\
\text { Variation }\end{array}$ \\
\hline Schmittenbach & 10 & 11.0 & 1.0 & 9.0 \\
Urslau & 56 & 57.3 & 6.4 & 11.2 \\
Strobler Weissenbach & 45 & 20.3 & 2.5 & 12.3 \\
Forstaubach & 57.2 & 59.7 & 8.4 & 14.0 \\
\hline
\end{tabular}

\section{RESULTS}

The RMSE as a measure of quality ranges between 1.0 and $8.4 \mathrm{~m}^{3} / \mathrm{s}$. The percentage deviation from the peak discharges lies in a range between 9 and 14 .

\section{INSIGHTS FOR THE DESIGN PRACTICE}

For calculation of design parameter in torrent catchments with complex terrain and rainfall process characterized by a high temporal and spatial variability these findings are useable for practical applications. General a good agreement between calculated and observed runoff can be pointed out. Deviations are found mostly on the falling limb, the peak discharge fits well and can be used for determination of the necessary design runoff. Due to field observations and event documentations and analyses, $\mathrm{CN}$-values were predefined. For the forested areas, we used values from 55 to 60 , for grass land areas 60-65 and for human areas 75 . The commonly used SCS unit hydrograph for modelling the direct runoff resulted in a good outcome. The used recession method to calculate the streamflow hydrograph and fit the falling limb provided only a slight improvement.

\section{REFERENCES}

[1] Herrnegger, M., Nachtnebel, H.P. \& Schulz, K., From runoff to rainfall: inverse rainfall-runoff modelling in a high temporal resolution; Hydrol. Earth Syst. Sci., 19, pp. 4619-4639, Online. www.hydrol-earth-syst-sci.net/19/4619/2015/. 2015.

[2] Moser, M.S. \& Mehlhorn, T.F., Measured rainfall-runoff relationships in torrential catchments - insights for the design practice; Zeitschrift für Wildbach, Lawinen, Erosions und Steinschlagschutz. Journal for Torrent, Avalanche, Landslide and Rock Fall, 173, 2014. 